\title{
10-Week Hatha Yoga Increases Right Hippocampal Density Compared to Active and Passive Control Groups: A Controlled Structural cMRI Study
}

Malvina Garner*, Wolfgang Reith and Christoph Krick

Department of Neuroradiology, University of Saarland, Homburg, Saarland, Germany

\section{Correspondence to:}

Malvina Garner

Department of Neuroradiology

University of Saarland, Homburg

Saarland, Germany

Tel: +49176/70328706

E-mail: malvina.garner@uni-saarland.de,

garnermalvina@web.de

Received: October 15, 2018

Accepted: January 17, 2019

Published: January 22, 2019

Citation: Garner M, Reith W, Krick C. 2019. 10Week Hatha Yoga Increases Right Hippocampal Density Compared to Active and Passive Control Groups: A Controlled Structural cMRI Study. J Neuroimaging Psychiatry Neurol 4(1): 1-11.

Copyright: ( 2019 Garner et al. This is an Open Access article distributed under the terms of the Creative Commons Attribution 4.0 International License (CC-BY) (http://creativecommons. org/licenses/by/4.0/) which permits commercial use, including reproduction, adaptation, and distribution of the article provided the original author and source are credited.

Published by United Scientific Group

\begin{abstract}
Background: The current study was designed to evaluate potential Yoga specific changes of brain structure in comparison with an active sport group and a passive control group.

Materials and Methods: We conducted a longitudinal structural MRI study to investigate changes in gray matter (GM) density following a Yoga intervention. In order to check the repeatability of the results two data acquisition periods (cohorts) with the same study design were done. Yoga naive subjects $(n=19 / n=$ 20) received a Yoga intervention once a week for 75 minutes over a period of 10 weeks. Control groups included active sport subjects $(n=10 / n=22)$ and passive subjects $(n=17 / n=14)$. All participants could choose their group assignment by their own preference. A longitudinal and group comparison was done by voxelbased-morphometric analyses before and after the intervention. In addition, blood pressure was taken before and after the study period as a controlling instrument. Finally, the results of the two cohorts were reported into a comprising data set for a general conclusion on Yoga effects.
\end{abstract}

Results: Initially, hippocampal GM density in the Yoga group was significantly lower than in both control groups already before the intervention. It was equally and independently present in both cohorts. The longitudinal MRI measurements showed a significant increase in the right hippocampal GM density as a specific effect of the Hatha Yoga intervention. Coincidentally, the blood pressure measurement detected a significant reduction in both systolic and diastolic blood pressure in the Yoga group but not in the sport or passive group.

Conclusions: Various neurodegenerative and neuropsychiatric diseases as well as long lasting stress lead to structural shrinkage of the hippocampal GM. In contrast, stress reduction was shown to be associated with an increase in the hippocampal GM density. The Yoga specific effect in this study can be considered as positive impact on both stress management and its underlying neural structure. These effects have been already proven in prevention and therapy of neurodegenerative and neuropsychiatric diseases. The Yoga-induced stress reduction can be furthermore supported by the findings of blood pressure reduction. Blood pressure is well known as an indirect indicator for stress reduction. Since the GM density was detected lower in the two Yoga cohorts twice compared to both control groups, one may postulate a pre-existing but unconscious higher stress vulnerability when voluntarily deciding for the Yoga intervention.

\section{Keywords} exercise

Hatha yoga, Hippocampus, Structural MRI, Stress, Blood pressure, Physical 


\section{Introduction}

Hatha Yoga is a method which was developed in the 15 th century in India. In a holistic approach it aims at a natural balanced physical and mental state of well-being [1]. It contains physical as well as breathing, relaxation and meditative exercises. In modern society Yoga was initially associated with specific body contortions and acrobatic poses. It became not only popular due to its positive physical and psychological effects in the healthy [2-4]. It also showed preventive and therapeutic effects in patients with various common diseases, including cardiovascular diseases [5-7], especially high blood pressure $[8,9]$, neuro-psychiatric disorders $[10$, $11]$ such as ADHD $[12,13]$, post-traumatic stress disorder $[14,15]$, anxiety disorders [16-18], depression [19-21] and schizophrenia $[22,23]$. In particular, the significant reduction in stress [24-26 ], and the positive effects on diseases that often occur in old age, such as Alzheimer's [27] and Parkinson's [28], and where conventional medicine is still limited in cure, makes Yoga an exciting current therapeutic modality.

Structural changes in the brain may provide a neurobiological explanation. With the background of neuronal plasticity $[29,30]$ and the already proven brain morphological effects through systematic motor [31], and cognitive exercises [32], it can be expected that structural brain changes in the cMRI can be demonstrated by a multi-week Hatha Yoga practice. The structural effects of meditation have already been well investigated [33] along with other similar mind body practices like MBSR [34-36] as well as physical exercises [37]. However, the question of a specific structural effect of Yoga has hardly been explored so far. Three cross-studies of longterm Yoga practitioners compared to naïve subjects showed an increase in volume in different brain areas [38-40]. One recent longitudinal study examined older people who regularly practiced Yoga over a period of 6 months and showed an increased hippocampal volume [41]. "Om Chanting”, which is used in Hatha Yoga as a "mind-sound-resonance" technique, showed an influence on the limbic system [42]. A review study includes also fMRI and EEG studies demonstrating effects of Yoga practices [43].

In summary, one can postulate a structural effect of Yoga on brain areas that are related to learning, attention, emotional regulation and stress response [43-48]. In particular, stress is an archaic emotional function which is described in neuronal morphological models [49]. The hippocampus is especially known for its stress vulnerability [50]. A shrinkage of the hippocampus has been shown to be associated with increased stress [51-54]. As increasing stress resistance after Yoga training altered hippocampal structure, we hypothesize an influence of Yoga on stress related neuronal networks. Due to above described known association between high stress sensitivity and smaller hippocampal volume we expect an increasing hippocampal structure. In addition, physical exercise has been shown to be effective in increasing hippocampal structure [55]. Hence, an active control group was included to reveal specific Yoga effects on the Hippocampus.

\section{Methods}

\section{Study design}

In a longitudinal, controlled, non-randomized experimental study including two cohorts of in total 102 subjects were recruited from the Medical University of Saarland via local and Facebook advertisement. Mean age was 22.7 years ( \pm SD 2.3 ; age range: $18-29$ years) in the first cohort and 22.9 years ( \pm SD 4.4 ; age rage $18-49$ years in the second. In order to be able to specify a structural effect through a Hatha Yoga training and to minimize the noise caused by internal or external influences [56-58] the Yoga group was compared to an active Hatha Yoga comparable sports practice as well as to a passive control group. Concerning methodological setting, the study could not be conducted as a double blind because of the knowledge of each subject to the self-chosen group assignment. When recruiting the subjects, all groups were equally instructed in respect of the study design but without explanation of the study's hypothesis in order to prevent suggestive expectation of the subjects.

In order to check the repeatability of the results two data acquisition periods (cohorts) with the same study design were done. For a general analysis the two cohorts were comprised two one dataset.

The participants underwent either Yoga courses ( $\mathrm{n}=39$; 5 males; 34 females) or sportive exercises $(n=32 ; 1$ male; 31 females). The Yoga intervention consisted of a Yoga practice, which was carried out once a week for 75 min over a period of 10 weeks. The subjects of the Yoga group had not practiced Yoga or similar mind-body exercises for at least 6 months. The sport group conducted an anaerobic fitness-oriented stretching and strengthening training program, which was similar to the body motions contained in the Hatha-Yoga class. Yoga specific elements, however, were not included. The sport group also consisted of participants, which had not performed sports activities for at least 6 months. The passive group ( $\mathrm{n}=$ 31; 10 males; 21 females) didn't change its daily habits. All subjects participated voluntarily, signed an informed consent document and received compensation (a copy of their brainimage) for their participation. The study was approved by the Ethics Committee of the University of Saarland. It was funded financially by the Saarland University (Committee of Research).

The longitudinal study consisted in two testing times, before and after the study period. Data acquisition comprised both MRI scans and blood pressure measurements according to the principle of Riva-Rocci [59]. Participants were included in the study if they self-reported being physically and psychologically healthy, with no history of neurological disorders, no abuse of alcohol or any other drugs including psychotropic medication. They were excluded for contra-indication for MRI scanning (i.e. metallic implants, claustrophobia) or in case of noncompliance at second measurements.

\section{Intervention}

All participants from the Yoga and the sport control 
group completed 10 hours of practice weekly for 10 weeks on average. The yoga course was given by the researcher formally trained in Hatha Yoga at SVYASA Yoga University. The practices included physical postures (Yogāsanas), breathing practices (Pranayama: Nadhi shouthi; cleansing techniques: Kaphalabhati), relaxation techniques and meditation with emphasis placed on bringing full awareness to the moment-tomoment experience and a non-harming attitude towards the body with a compassionate, non-judgmental mind. The Hatha Yoga program has been described extensively by SVYASA Yoga University in Bangalore [60].

The subjects of the sport control group participated in the following exercise programs once a week during the intervention period: abdominal-leg-butt training (60 minutes), body workout (45 minutes) and/or core training (60 minutes). All three sports programs included movements with similar muscular tension and stretching exercises as well as warm-up exercises, as used in Yoga training. Breathing exercises, meditation and relaxation techniques as used in the Hatha Yoga intervention were not included. The three courses were basically the same in the set-up and the practice sessions. They were taught by official trainers employed by the University of Saarland.

The Yoga and sports courses were taught always in a consistent style using the same workflow and instructions. The composition of the exercise elements with the appropriate time intervals is shown in table 1 and 2 .

Table 1: Structure and temporal organization of the Hatha Yoga course.

\begin{tabular}{|l|l|}
\hline \multicolumn{1}{|c|}{ Hatha Yoga } & \multicolumn{1}{c|}{ Time } \\
\hline 1. Breathing exercises & 10 minutes \\
2. Instant Relaxation Technique (IRT) & 2 minutes \\
3. Loosening exercises & 5 minutes \\
4. Quick Relaxation technique (QRT) & 3 minutes \\
5. Surya Namascar & 10 minutes \\
6. Asanas & 25 minutes \\
7. Deep Relaxation Technique (DRT) & 10 minutes \\
8. Pranayama and meditation & 10 minutes \\
\hline
\end{tabular}

Table 2: Structure and temporal organization of the sport group.

\begin{tabular}{|l|c|c|c|}
\hline & $\begin{array}{c}\text { Belly Beg } \\
\text { Bottom }\end{array}$ & $\begin{array}{c}\text { Body } \\
\text { Work Out }\end{array}$ & $\begin{array}{c}\text { Core } \\
\text { Training }\end{array}$ \\
\hline Warm-up exercises & 10 minutes & 10 minutes & 10 minutes \\
\hline $\begin{array}{l}\text { Strengthening } \\
\text { exercises }\end{array}$ & 40 minutes & 25 minutes & 40 minutes \\
\hline Stretching exercises & 5 minutes & 5 minutes & 5 minutes \\
\hline $\begin{array}{l}\text { Extra time for } \\
\text { explanation }\end{array}$ & 5 minutes & 5 minutes & 5 minutes \\
\hline
\end{tabular}

\section{Data acquisition}

To measure brain changes before and after the intervention, a structural 3-Tesla cMRI scan was performed at the Neuroradiological Department of Saarland University in Homburg (Saar) two weeks before and two weeks after the intervention. High resolution, 3-dimensional data sets of the whole brain were collected with a Siemens Magnetom Skyra
3.0 Tesla scanner with standard head coil using a T1 weighted MPRAGE-sequence, consisting of 192 sagittal slices (Pixel. Spacing: 0,9375 × 0,9 × 0,9 mm; Matrix: 256 x 256 Pixel; TI $=1000 \mathrm{~ms} ; \mathrm{TE}=2,13 \mathrm{~ms} ; \mathrm{TR}=1900 \mathrm{~ms} ; \mathrm{FoV}: 0,9375 \times 256$ $=240 \mathrm{~mm}$ ). Image analysis was performed with voxel-based morphometry Version 8 (VBM8-Toolbox Manual http:// dbm.neuro.uni-jena.de/vbm8/vbm8-manual.pdf). Tools within the SPM8 neuroimaging statistical software (Statistical Parametric Mapping, Welcome Department of Cognitive Neurology, London, UK, www.fil.ion.ucl.ac.uk/spm) based in MATLAB (Mathworks Inc., Natick, Massachusetts, USA) were used for further processing. VBM permits an automated voxel-wise whole-brain statistical comparison of the entire brain [61]. MRI images were initially normalized to the same stereotactic space, segmented into gray matter (GM), white matter (WM) and cerebrospinal fluid (CF) using the standard unified segmentation model in SPM8 [62, 63] smoothed with a $10 \mathrm{~mm}$ full width at half maximum Gaussian kernel to reduce the noise. The local distribution of GM, WM, and CF compartment were not altered by this process, nor the density values represented by the local concentration gradients.

The pre-processed GM datasets were further used for statistical analysis. A flexible factorial analysis was performed in SPM8, in order to identify those brain regions with significantly increased and decreased GM density of the whole brain following participation in the Yoga program compared to the sport and passive group. Given the hypothesis on a whole brain analysis, significance level was set at uncorrected $P<0.05$. Only those clusters which showed a significant group effect according to the Yoga intervention were selected for data exportation. The extracted data (inter- and intragroup comparisons) as well as blood pressure variables were further statistically processed via SPSS version 24 .

\section{Results}

Both the pre- and post-data of the systolic and diastolic blood pressure detected a normal range in the three groups. After the study period the systolic blood pressure (mean: $-6,6 \mathrm{mmHg}$,

Table 3: Significant increase of GM density in the Yoga group compared to the sport group from Pre- to Post training in the exploratory whole brain analysis (Yoga > Sport). STS: Superior Temporal Gyrus; BA 44: Brodmann Areal 44

\begin{tabular}{|l|c|c|c|c|}
\hline Region & Cluster & $\begin{array}{c}\text { Cluster } \\
\text { Level }\end{array}$ & $\begin{array}{c}\text { MNI } \\
\text { Coordinates }\end{array}$ & T of Peak \\
\hline $\begin{array}{l}\text { (peak of } \\
\text { cluster) }\end{array}$ & size k & P-value & $\mathbf{x , y , ~ z ~}$ & Voxel \\
\hline $\begin{array}{l}\text { Right } \\
\text { Hippocampus }\end{array}$ & 81 Voxel & $20 / 1 /-22$ & $20 / 5 /-27$ & 3,74 \\
\hline Left STS & 51 Voxel & $50 /-28 /-4$ & $-50 /-24 /-9$ & 3,41 \\
\hline Right STS & 10 Voxel & $48 /-23 /-9$ & $48 /-19 /-14$ & 3,07 \\
\hline Left superior & 34 Voxel & & & \\
\hline Orbital Gyrus & & & & \\
\hline Maximum 1 & & $-17 / 41 /-13$ & $-17 / 45 /-18$ & 2,95 \\
\hline Maximum 2 & & $-17 / 37 /-15$ & $-17 / 41 /-20$ & 2,80 \\
\hline Right BA44 & 28 Voxel & $47 / 8 / 2$ & $47 / 12 / 21$ & 3,21 \\
\hline
\end{tabular}


SD: 9,46) and diastolic blood pressure (mean: $-7,5 \mathrm{mmHg}$, SD: 9,64) were significantly reduced only in the Yoga group but not in the sport or passive group $(\mathrm{p}<0,05)$.

The VBM analysis combined with the Anatomy Toolbox revealed a significant increase in GM density in the Yoga group compared to the sport group at five locations: right hippocampus, left and right superior temporal sulcus (STS), left superior orbital gyrus and Brodman area 44 (BA44) (Table 3).

Comparison of GM density between the Yoga group and the sport group (Yoga < Sport) revealed three significant clusters in the VBM analysis: Cluster 1 is in accordance to the localization above the left insula. Cluster 2 indicates a maximum over the right insula and over the right inferior frontal gyrus. In cluster 3 two maxima are displayed over the inferior parietal lobe and a maximum over the left oblique gyrus (Table 4).

Table 4: Significant decrease of GM density in the Yoga group compared to the sport group from Pre- to Post training in the exploratory whole brain analysis (Yoga $<$ Sport)

\begin{tabular}{|l|c|c|c|c|}
\hline Region & Cluster & $\begin{array}{c}\text { Cluster } \\
\text { Level }\end{array}$ & $\begin{array}{c}\text { MNI } \\
\text { Coordinates }\end{array}$ & $\begin{array}{c}\text { T of } \\
\text { Peak }\end{array}$ \\
\hline (peak of cluster) & size k & P-value & $\mathbf{x , y , ~ z ~}$ & Voxel \\
\hline Cluster 1: & 89 Voxel & $-36 / 8 / 15$ & $-36 / 12 / 10$ & 4,32 \\
\hline left Insula & & & & \\
Cluster 2: & & $36 / 11 / 15$ & $36 / 15 / 10$ & 2,82 \\
$\begin{array}{l}\text { right Insula } \\
\text { right inferior } \\
\text { frontal Gyrus }\end{array}$ & 35 Voxel & $39 / 8 / 15$ & $39 / 12 / 10$ & 3,17 \\
\hline Cluster 3: & & & & \\
\hline $\begin{array}{l}\text { Max 1: left inferior } \\
\text { parietal lobus }\end{array}$ & & & & \\
$\begin{array}{l}\text { Max 2: left inferior } \\
\text { parietal lobus }\end{array}$ & 109 Voxel & $-38 /-56 / 44$ & $-38 / 52 / 39$ & 3,25 \\
$\begin{array}{l}\text { Max 2: Left } \\
\text { angular Gyrus }\end{array}$ & & $-35 /-58 / 39$ & $-42 /-49 /-42$ & 2,91 \\
& & & & 2,95 \\
\hline
\end{tabular}

The contrast "Yoga > Passive Controls" and "Yoga < Passive Controls" entered in SPM8 did not provide any significant clusters.

In order to prove Yoga specific effects there must be either a significant intergroup difference or a significant longitudinal intragroup difference. According, to these two conditions only a significant increase in the right hippocampal GM density as a specific effect of the Hatha Yoga intervention was found, while the density of GM in the sport group decreased significantly after the intervention. In the control group the GM density did not change significantly (Table 5 and 6, Figure 1).

Table 5: Pre-post comparison between the three groups regarding GM density of the right hippocampus using Wilkoxon test.

\begin{tabular}{|c|c|c|c|}
\hline & Median-pre & Median-post & p-value \\
\hline Yoga & 0,43 & 0,44 & $0,036^{*}$ \\
\hline Sport & 0,59 & 0,57 & $0,004^{*}$ \\
\hline Passive & 0,58 & 0,59 & 0,710 \\
\hline
\end{tabular}

One thing of note is the fact that the GM density of the
Table 6: Pairwise group comparison of pre- post change in GM density of the right hippocampus using adjusted significance in the KruskalWallis test.

\begin{tabular}{|c|c|}
\hline & p-value \\
\hline Yoga - Sports & $0,002^{\text {** }}$ \\
\hline Yoga - Passive & 0,958 \\
\hline Sport - Passive & 0,078 \\
\hline
\end{tabular}
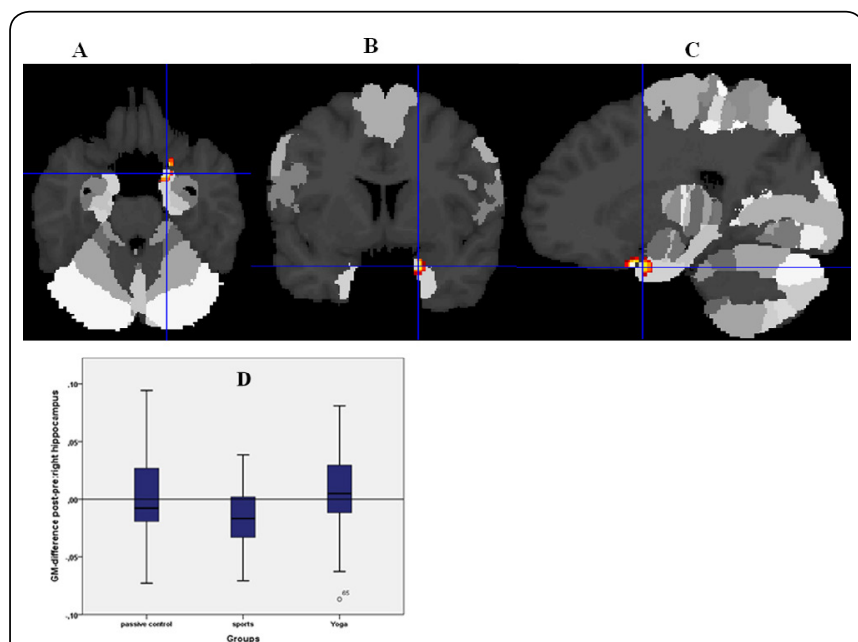

Figure 1: 3-dimensional representation of the SPM8 evaluation for "Yoga > Sport". Whole brain analysis identifies GM density increases in the right hippocampus (MNI coordinates $\mathrm{x}=20(\mathrm{~A}), \mathrm{y}=5(\mathbf{B}), \mathrm{z}=-27(\mathbf{C})$ in the Yoga group marked red. Voxels (thresholded at $p=0.05$ ) are overlaid over the group-averaged brain. (D) Change in GM density in the right hippocampus from the Pre to the Post time-point in the Yoga and the control groups; error bars show $95 \%$ confidence interval.

hippocampus in the Yoga group was significantly lower than in both control groups before the intervention (Table 7, Figure 2). The two-peak distribution was independently and equally present in both cohorts of the winter and in the summer semester.

Table 7: Pairwise group comparison of the pre-measurement: GM density of the right hippocampus, using adjusted significance in the Kruskal-Wallis test.

\begin{tabular}{|c|c|}
\hline & p-value \\
\hline Yoga - Sports & $0,000^{* * * *}$ \\
\hline Yoga - Passive & $0,000^{* * * *}$ \\
\hline Sports - Passive & 1,000 \\
\hline
\end{tabular}

In order to further investigate this preexisting group difference, the question was whether the absolute density of GM, WM and CF were different at the point of premeasurement. Here the Yoga group attracted attention with a higher density of all three compartments compared to the sport group. Nevertheless, these differences between the Yoga and sport group were not significant $(\mathrm{p}>0.05)$. The passive control group, on the other hand, showed the highest density of the 3 compartments, this difference was significant for both the sport group $(\mathrm{p}<0.05)$ and the Yoga group based on the density of white matter $(\mathrm{p}<0.05)$ (Table 8$)$.

By comparing the total brain density of all three groups, calculated from the addition of GM density, WM and CF, a 

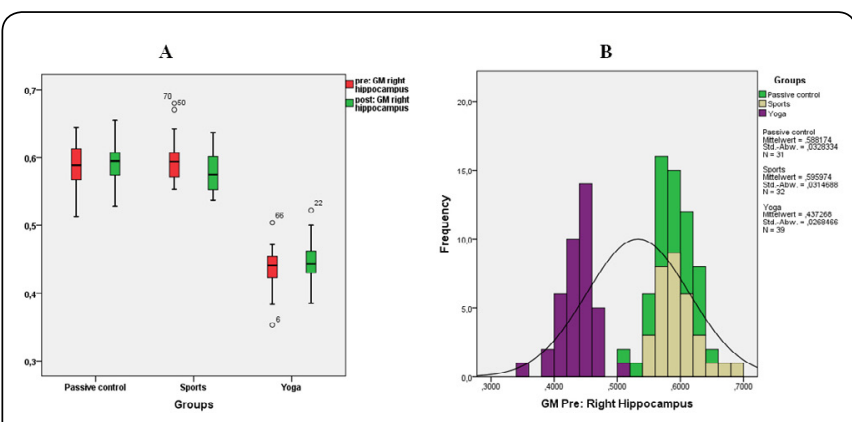

Figure 2: Figure A demonstrates the longitudinal course of hippocampal GM density in the three groups. The pre-GM values of the Yoga group were significantly lower compared to the pre-data of both control groups. The two-peak distribution in figure $\mathbf{B}$ illustrates the Yoga group representing a different population compared to a uniform population of both control groups concerning the hippocampal GM density. The twopeak distribution was independently and equally present in both cohorts. Outliers were not shown in either cohorts.

Table 8: Total GM, WM and CSF density as well as total brain density (GV) for all three groups; Descriptive statistics with indication of median and span.

\begin{tabular}{|l|c|c|c|c|}
\hline & GM-Pre & WM-Pre & CSF-Pre & GV-Pre \\
\hline Yoga & $\begin{array}{c}703,7 \\
(564,9-788,1)\end{array}$ & $\begin{array}{c}487,7 \\
(385,0-622,2)\end{array}$ & $\begin{array}{c}211,7 \\
(171,1-266,9)\end{array}$ & $\begin{array}{c}1404,6 \\
(1131,5-1665,7)\end{array}$ \\
\hline Sport & $\begin{array}{c}674,8 \\
(520,5-822,9)\end{array}$ & $\begin{array}{c}481,5 \\
(408,5-618,8)\end{array}$ & $\begin{array}{c}203,8 \\
(174,2-264,2)\end{array}$ & $\begin{array}{c}1385,1 \\
(1148,0-1691,4)\end{array}$ \\
\hline Passive & $\begin{array}{c}723,8 \\
(627,3-847,4)\end{array}$ & $\begin{array}{c}539,6 \\
(431,4-658,0)\end{array}$ & $\begin{array}{c}221,5 \\
(195,1-265,2)\end{array}$ & $\begin{array}{c}1495,1 \\
(1271,1-1726,9)\end{array}$ \\
\hline
\end{tabular}

Table 9: Pairwise group comparison of absolute GM, WM and CSF density and of total brain density $(\mathrm{GV})$ in the pre-measurement as well as for the ratio GM/GV; Adjusted significance in the Kruskal-Wallis test for the absolute GM pre and WM pre, Mann-Whitney U Test for GM/GV pre.

\begin{tabular}{|c|c|c|c|c|c|}
\hline & p-value & p-value & p-value & p-value & p-value \\
\hline & GM-Pre & WM-Pre & CSF-Pre & GV-Pre & GM/GV \\
\hline Yoga - Sport & 0,199 & 1,0 & 1,0 & 0,630 & 0,603 \\
\hline Yoga - Passive & 0,064 & $0,012^{* *}$ & 0,216 & $0,013^{* *}$ & 0,504 \\
\hline Sport - Passive & $0,000^{* * *}$ & $0,02^{* * *}$ & $0,036^{*}$ & $0,000^{* * * *}$ & 0,978 \\
\hline
\end{tabular}

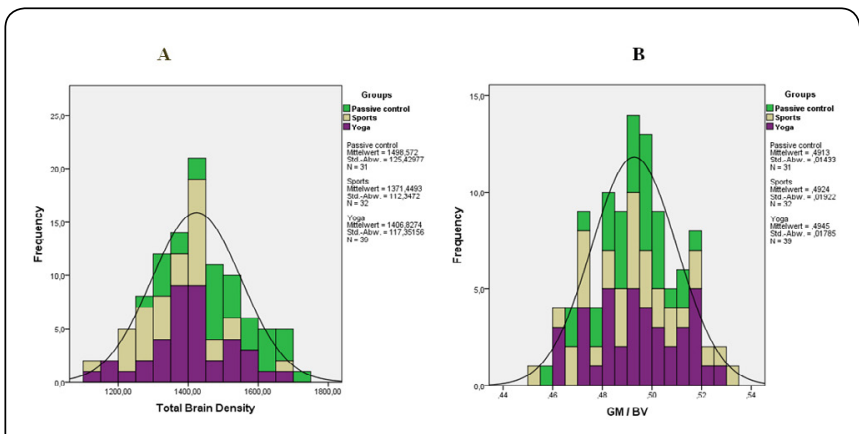

Figure 3: Frequency distribution of the total brain density $(B V)$, calculated from the addition of GM, WM and CF density (A), and frequency distribution of GM density and total brain density (GM/BV) ratio (B).

significant group difference between the Yoga and sport group to the passive controls was found again $(\mathrm{p}<0.05)$ (Table 9). The body size analyzes of the three groups showed the Yoga subjects slightly taller compared to the sport group (body height Yoga; mean: 1.68; SD: 1.50-1.88; body height sport; mean: 1.69; SD
1.52-1.95). The passive control group, however, stood out with a mean height of 1.76 meters (body height passive control; mean: 1.76; SD: $1.58-2.0$ ). In a linear regression analysis, a correlation between the total brain density with the height and sex of the subjects was found. Here, the total brain density was chosen as a dependent variable. For the independent variables, body height was used as the first level and gender as the second level. The size hereby explains $29.1 \%$ of the density of the GM (body size: corrected R square $=0.291, \mathrm{~F}=42.465, \mathrm{p}$ $=0.000$ ), the gender additionally $13 \%$ (sex: corrected $\mathrm{R}$ square $=0.421, \mathrm{~F}=37.669 \mathrm{p}=0.000)$. According, to Cohen (1992) this corresponds to a strong effect.

Finally, this difference in density relates only to the hippocampus, but neither to the sum of all three compartments (Figure 3A) nor to the relation of GM to the total brain (Figure 3B).

\section{Discussion}

This longitudinal study demonstrates significant increases in GM density in the right hippocampus as well as a significant reduction in systolic and diastolic blood pressure following a ten-week Hatha Yoga course compared to a sport group and a passive group.

\section{Discussing the effect on blood pressure}

A positive correlation between chronic stress and high blood pressure as well as between stress reduction and reduction in blood pressure is well known [64-66]. Moreover, the effect of blood pressure reduction due to a Yoga intervention has been already described in numerous studies [8, 9, 67], even after short intervention periods [68-72]. Consequently, the Yoga participants showed a significant reduction of blood pressure in both cohorts despite a normal blood pressure in both the pre- and post-measurement. The hypotensive effect of Yoga in even normotensive subject's points towards an overall regulating effect on blood pressure. This underlines the potential of Yoga in influencing the autonomic nervous system. Therefore, a relationship between Yoga-induced stress reduction over central nervous processes $[45,73,74]$ can be postulated. Hence, discovering these processes invokes a very new field of brain research.

\section{Discussing the structural effect on the hippocampus}

The hippocampus has been postulated to intermediate emotional regulation [75, 76], learning, memory consolidation [77], spatial orientation [78-80], and stress regulation circuits [50]. It seems also be associated with breathing rhythms [81-85].

May A [86], discussed the relationship between large scale GM alteration and microscopic tissue-related processes: Neuronal changes can be understood as "rearrangement of network homeostasis balancing the integration of neuronal activity, neurotransmitter release, neuronal (and perhaps glial) morphogenesis and changes in network formation including formation and elimination of synaptic structures". Moreover, adult neurogenesis occurs predominantly in the hippocampus [87]. Thus, our results of structural increase in 
the hippocampus' GM density could be impacted by higher involvement of hippocampal functions and consecutive structural enhancement of the involved brain tissue. Future research will be needed to investigate the underlying neural mechanisms.

An effect on the hippocampus towards a larger volume or density has already been observed in various Yoga, mindbody, meditation and sports studies [38-41]. Besides the hippocampus those studies marked out also other brain regions. As these studies report a more intensive or much longer period of Yoga, mind-body or meditation practice, Yoga specific changes can be concluded to be dependent on intensity and duration of the intervention. A longer and more intensive intervention would be desirable in order to be able to prove additional clusters, as they were found in other studies on this topic.

Furthermore, since the effect on the hippocampus is not only passively controlled, but also had existed amongst the sport control group, it can be assumed that the Yoga specific elements such as meditation, relaxation and breathing exercises were partly responsible for the effect and not the strengthening and stretching elements in anaerobic exercises [88]. A clear distinction between aerobic and anaerobic training was shown [89]. While aerobic moderate endurance training resulted in an increase in volume in the hippocampus, this could not be achieved with intensive anaerobic training. This may explain the lack of increasing structural effect in the active sports group.

Overall, this study doesn't provide a specific answer which element of the Hatha Yoga training has the most impact on the structural effect.

Considering the proposed particular fundamental role of the hippocampus in emotional regulation the hippocampus seems to be responsible especially for rational evaluation of situations $[90,91]$. Since sober observation of the actual moment is a part of the meditative elements in Hatha Yoga, this practice may contribute to an improvement in emotional regulation and thus an increase in hippocampal density. This thesis is supported by theoretical models of yoga effects [45, $92,93]$ as well as by various studies on meditation and MBSR which showed an increased hippocampal density or volume [34, 94-96].

The hippocampus also plays a crucial role in long-term memory consolidation [97] and learning [32, 98]. Working memory has been shown several times to improve with yoga practice $[45,99,100]$. An association between regular longterm yoga practice and changes in brain structure and functions involved in working memory has been recently suggested as well [40]. By learning new skills and techniques on the one hand as well as keeping maintenance of concentration in each aspect of a Hatha Yoga lesson the structural changes can also be explained by cognitive training during the Hatha Yoga practice.

Furthermore, the balance exercises, which are an integral part of the Yoga exercises, could contribute to the effect in the hippocampus taking into account the significant role of the right hippocampus in spatial orientation [101] and the consolidation of motor sequences [102]. Several studies have shown structural increase of the hippocampus after interventions on balance [103-106].

However, it should be noted that those studies on balance have found an increase not only in the right but also in both the left and the right hippocampus [103-106]. Looking at the results of the Yoga and mind-body studies, a similar inhomogeneous picture of the affected hemisphere is shown $[34,40,41]$.

Additionally, the conscious breath synchronized physical exercises (Asanas) as well as special breathing techniques (Pranayama) as a Yoga typical element which distinguishes Hatha Yoga from strengthening and stretching exercises may also contribute to the structural increase of the hippocampus in the Yoga group but not in the sport group. The hippocampus has been postulated to be directly involved in respiratory regulation and cognitive function [83] and seems therefore to be directly affected by the breathing rhythm [107].

As Zelano et al. [81] found activation of the hippocampus only for nasal breathing, but not for mouth breathing, the focused nasal practiced breathing in Hatha Yoga here is postulated to play a role in the structural changes of the hippocampus.

Furthermore, in the Hatha Yoga intervention "Kapalabhati” breathing performs a controlled hyperventilation. The consequent hypocapnia leads to a constriction of vessels in the brain, leading to a short-term relative hypoxia. This fits very well with the results of Bousama et al. [108] who postulated in their work intermittent hypoxia as the key factor for neurogenesis modulation in the hippocampus. They hypothesized that activation of neurogenesis is a reaction to hypoxia-induced neuronal loss, thereby contributing relative hypoxia as a neuroprotective mechanism [109-111].

Especially the ventral part of the hippocampus, which was changed in the current study, was found to be a part of the limbic network that contributes to modulating the activities of respiratory-related cells in the ventrolateral medulla, postulating the hippocampus as a limbic breathing control sites [84].

Practicing regular long lasting in- and expirations is an ongoing part of every Yoga lesson. The effect of augmented breaths [112] as well as effects of Yoga breathing practices [68] has shown to be associated with changes in blood pressure and heart rate. Breath frequency and indurance are found to be strongly influenced by negative and positive emotions [110, 113]. Therefore, it is tempting to speculate that the breathing element in Hatha Yoga practice represents an important role for the effect on the hippocampus by influencing circuits between neurons of the ventral hippocampus and brainstem nuclei [112].

Furthermore, a smaller volume of the hippocampus has been postulated by various studies to be associated with increased stress [51-54]. Stress reduction in contrast was shown to be associated with an increase in the density of the hippocampal GM [34] as well as with an increase in BDNF 
levels, a neurotrophic factor [114] which is predominantly produced by the hippocampus. Therefore, BDNF may contribute to structural regeneration due its neuroprotective effects [115]. An increase of neurotrophic factors, including BDNF, through Yoga practice has been already described $[116,117]$. As Hatha Yoga training can't be described as an aerobic physical exercise, which has been shown to increases BDNF levels $[118,119]$, Yoga specific elements like breathing patterns, relaxation and mental training are suspected to play a crucial role in modulating neuroprotective factors and to be responsible for the structural effect in the hippocampus. Furthermore, the increase in density of hippocampal GM in the present study may be considered as a structural correlate of both neuroprotective and stress-reducing effects through Yoga.

\section{Clinical contribution}

Various neurodegenerative diseases, such as Alzheimer's disease [120] and neuropsychiatric diseases, such as depression [121, 122], anxiety disorder [123], post-traumatic stress disorder [124] and schizophrenia [125] lead to structural shrinkage of the hippocampus. In this context, several studies have pointed the positive impact of Hatha Yoga on symptoms in neurological disorders [13, 126-129].

An increase in hippocampal density and volume has been reported in patients after drug therapy [130], psychotherapeutic [131] or other therapeutic interventions [132]. The morphological changes reported in the current may provide a structural explanation for the positive influence of Yoga on the mentioned disorders [38]. Moreover, postulating the hippocampal structural changes by the overall stress reducing effect of the Yoga training it can be assumed that Yoga is able to bring enhancements in various stress related diseases.

\section{Group differences of hippocampal GM density}

We found significantly lower pre-existing hippocampal GM density in the Yoga group compared to both control groups. This finding was shown equally and independently twice in the two cohorts, although this was not part of our initial hypothesis. This difference in low density at the beginning of the interventions related to the hippocampus not to the entire brain.

Further clarification of this finding showed an even slightly higher density of all three compartments in the Yoga group compared to the sport group. Furthermore, the passive group showed a significant higher total brain density compared to the Yoga and sport group. This constellation of total brain matter can be explained by a strong correlation between the total brain density with the body height and sex of the subjects. Considering the findings of many other studies, this result is not surprising $[133,134]$.

However, the gender related difference does not apply to the baseline values of the hippocampus. The passive group and the sport group ranged in the same value of GM density in the hippocampus. Thus, the significant lower baseline values in right hippocampal density in only the Yoga group can't be explained by the gender differences. The same applies to body height.

Sociodemographic data homogeneity existed in all three groups in terms of age, profession, state of health and day to day student life. Therefore, there must be another common distinguishing feature between the individuals of the Yoga group and the control groups.

Kanai and Rees [135], postulate in their study that certain characteristics such as cognition, intelligence, behavior, learning ability or personality traits can be predicted via the local structure of the GM and WM. Moreover, a recent fMRI study provided multivariate pattern of stressor-evoked brain activity as a phenotype that may be responsible for individual differences in blood pressure reactivity [136].

In particular, the hippocampus has been shown to be highly susceptible to stress [137]. Grigoryan and Segal [138] could show that a prenatal small hippocampus volume was predictive of the personal stress tendency. Another monozygotic twin study proposed a reduced hippocampal volume to be a predisposing factor for the development of PTSD following a trauma [139].

Finally, which internal or external influences ultimately led to the decision of belonging to a group can only be treated hypothetically at this point. One possible explanation is that subjects who opted for Yoga intervention were more sensitive and vulnerable to stress factors and therefore chose Yoga intervention as a relaxation-promising method of intervention.

Further studies on this topic should therefore focus on randomization to rule out group bias. Also, the current study investigated mostly medical students with a mean age of 22 years. Mostly females attended the intervention groups. Generalization should therefore be limited to this population of individuals. Future studies will be required to test whether findings extend to other group populations in terms of age, profession and gender. The present study employed a large sample size, still replications and larger studies are necessary.

\section{Limitations}

- The assignment to the three different groups was not randomized due to the self-chosen assignment. However, individual constants (e.g. age, gender, body height, profession) didn't play a significant role in the paired testing performed in the longitudinal design. Thus, only the relative differences were analyzed.

- In contrast, interpretation of the cohort analysis concerned the absolute pre-data. The repeatability of the results in the cohort pre-data analysis speaks for a tangible finding. However, the study method was not accurate for this incident finding. Consequently, the results related to the pre-data must be carefully considered and interpreted. In the current study the significant lower baseline values in right hippocampal density in only the Yoga group can't be explained by gender or body height differences. Still, a repeat of the study should be carried out with attention to homogenous groups.

- Although the consecutive blood pressure measurements 
in one subject always took place at the same day time and under the same conditions, assessing blood pressure were only done a total of two times and, thus, may not be representative in giving the variation in blood pressure value throughout the day. Hence, only relative differences were regarded.

\section{Acknowledgment}

We thank our participants and the MRI staff for their significant support and cooperation. This research was supported financially by the University of Saarland. The funders had no role in study design, data collection and analysis, decision to publish, or preparation of the manuscript.

\section{Conflicts of Interest}

The authors declare no conflicts of interest.

\section{References}

1. Pradhan B. 2015. Yoga and mindfulness based cognitive therapy: a clinical guide. Springer, New York, USA.

2. Woodyard C. 2011. Exploring the therapeutic effects of yoga and its ability to increase quality of life. Int J Yoga 4(2): 49-54. https://doi. org/10.4103/0973-6131.85485

3. Ross A, Thomas S. 2010. The health benefits of yoga and exercise: a review of comparison studies. J Altern Complement Med 16(1): 3-12. https://doi.org/10.1089/acm.2009.0044

4. Büssing A, Michalsen A, Khalsa SBS, Telles S, Shermank KJ. 2012. Effects of yoga on mental and physical health: A short summary of reviews. Evid Based Complement Alternat Med 2012: 65410. https://doi. org/10.1155/2012/165410

5. Cramer H, Lauche R, Haller H, Steckhan N, Michalsen A. 2014. Effects of yoga on cardiovascular disease risk factors: a systematic review and meta-analysis. Int J Cardiol 173(2): 170-183. https://doi. org/10.1016/j.ijcard.2014.02.017

6. Manchanda SC, Madan K. 2014. Yoga and meditation in cardiovascular disease. Clin Res Cardiol 103(9): 675-680. https://doi.org/10.1007/ s00392-014-0663-9

7. Manchanda SC. 2014. Yoga--a promising technique to control cardiovascular disease. Indian Heart J 66(5): 487-489. https://doi. org/10.1016/j.ihj.2014.08.013

8. Hagins M, States R, Selfe T, Innes K. 2013. Effectiveness of yoga for hypertension: systematic review and meta-analysis. Evid Based Complement Alternat Med 2013: 649836. https://doi. org/10.1155/2013/649836

9. Tyagi A, Cohen M. 2014. Yoga and hypertension: a systematic review. Altern Ther Health Med 20(2): 32-59.

10. Meyer HB, Katsman A, Sones AC, Auerbach DE, Ames D et al. 2012. Yoga as an ancillary treatment for neurological and psychiatric disorders: a review. J Neuropsychiatry Clin Neurosci 24(2): 152-164. https://doi.org/10.1176/appi.neuropsych.11040090

11. Klatte R, Pabst S, Beelmann A, Rosendahl JS. 2016. The efficacy of body-oriented yoga in mental disorders. Dtsch Arztebl Int 113(12): 195202. https://doi.org/10.3238/arztebl.2016.0195

12. Ramsay JR. 2010. Nonmedication treatments for adult ADHD evaluating impact on daily functioning and well-being. American Psychological Association, Washington, DC, USA.

13. Balasubramaniam M, Telles S, Doraiswamy PM. 2012 Yoga on our minds: a systematic review of yoga for neuropsychiatric disorders. Front Psychiatry 3: 117. https://doi.org/10.3389/fpsyt.2012.00117
14. van der Kolk BA, Stone L, West J, Rhodes A, Emerson D, et al. 2014. Yoga as an adjunctive treatment for posttraumatic stress disorder: a randomized controlled trial.J Clin Psychiatry 75(6): e559-e565. https:// doi.org/10.4088/JCP.13m08561

15. Cramer H, Anheyer D, Saha FJ, Dobos G. 2018. Yoga for posttraumatic stress disorder - a systematic review and meta-analysis. BMC Psychiatry 18(1): 72. https://doi.org/10.1186/s12888-018-1650-x

16. Li AW, Goldsmith CA. 2012. The effects of yoga on anxiety and stress. Altern Med Rev 17(1): 21-35.

17. Cramer H, Lauche R, Anheyer D, Pilkington K, de Manincor M, et al. 2018. Yoga for anxiety. A systematic review and meta-analysis of randomized controlled trials. Depress Anxiety 35(9): 830-843. https:// doi.org/10.1002/da.22762

18. Hofmann SG, Andreoli G, Carpenter JK, Curtiss J. 2016. Effect of hatha yoga on anxiety: a meta-analysis. J Evid Based Med 9(3): 116-124. https://doi.org/10.1111/jebm.12204

19. Prathikanti S, Rivera R, Cochran A, Tungol JG, Fayazmanesh N. 2017. Treating major depression with yoga: a prospective, randomized, controlled pilot trial. PloS One 12(3): e0173869. https://doi. org/10.1371/journal.pone.0173869

20. Cramer H, Lauche R, Langhorst J, Dobos G. 2013. Yoga for depression: a systematic review and meta-analysis. Depress Anxiety 30(11): 10681083. https://doi.org/10.1002/da.22166

21. Zou L, Yeung A, Li C, Wei GX, Chen KW, et al. 2018. Effects of meditative movements on major depressive disorder: a systematic review and meta-analysis of randomized controlled trials. J Clin Med 7(8): 195. https://doi.org/10.3390/jcm7080195

22. Gangadhar BN, Varambally S. 2012. Yoga therapy for schizophrenia. Int J Yoga 5(2): 85-91. https://doi.org/10.4103/0973-6131.98212

23. Vancampfort D, Vansteelandt K, Scheewe T, Probst M, Knapen J. 2012. Yoga in schizophrenia: a systematic review of randomised controlled trials. Acta Psychiatr Scand 126(1): 12-20. https://doi.org/10.1111/ j.1600-0447.2012.01865.x

24. Chong CS, Tsunaka M, Tsang HW, Chan EP, Cheung WM. 2011. Effects of yoga on stress management in healthy adults: a systematic review. Altern Ther Health Med 17(1): 32-38.

25. Sharma M. 2014. Yoga as an alternative and complementary approach for stress management: a systematic review. J Evid Based Complementary Altern Med 19(1): 59-67. https://doi.org/10.1177/2156587213503344

26. Pascoe MC, Thompson DR, Ski CF. 2017. Yoga, mindfulnessbased stress reduction and stress-related physiological measures: a meta-analysis. Psychoneuroendocrinology 86 : 152-168. https://doi. org/10.1016/j.psyneuen.2017.08.008

27. Du Q, Wei Z. 2017. The therapeutic effects of yoga in people with dementia: a systematic review. Int J Geriatr Psychiatry 32(1): 118. https://doi.org/10.1002/gps.4538

28. Sharma NK, Robbins K, Wagner K, Colgrove YM. 2015. A randomized controlled pilot study of the therapeutic effects of yoga in people with Parkinson's disease. Int J Yoga 8(1): 74-79. https://doi. org/10.4103/0973-6131.146070

29. Gage FH. 2002. Neurogenesis in the adult brain. J Neurosci 22(3): 612613. https://doi.org/10.1523/JNEUROSCI.22-03-00612.2002

30. Markham JA, Greenough WT. 2004. Experience-driven brain plasticity: beyond the synapse. Neuron Glia Biol 1(4): 351-363. https:// doi.org/10.1017/s1740925x05000219

31. Draganski B, Gaser C, Busch V, Schuierer G, Bogdahn U, et al. 2004. Neuroplasticity: changes in grey matter induced by training. Nature 427(6972): 311-312. https://doi.org/10.1038/427311a

32. Draganski B, Gaser C, Kempermann G, Kuhn HG, Winkler J, et al. 2006. Temporal and spatial dynamics of brain structure changes during extensive learning. J Neurosci 26(23): 6314-6317. https://doi. org/10.1523/JNEUROSCI.4628-05.2006 
33. Tang YY, Britta BK, Posner MI. 2015. The neuroscience of mindfulness meditation. Nat Rev Neurosci 16(4): 213-225. https://doi.org/10.1038/ nrn3916

34. Hölzel BK, Carmody J, Vangel M, Congleton C, Yerramsetti SM, et al. 2011. Mindfulness practice leads to increases in regional brain gray matter density. Psychiatry Res 191(1): 36-43. https://doi.org/10.1016/j. pscychresns.2010.08.006

35. Gotink RA, Meijboom R, Vernooij MW, Smits M, Hunink MG. 2016. 8-week mindfulness based stress reduction induces brain changes similar to traditional long-term meditation practice - a systematic review. Brain Cogn 108: 32-41. https://doi.org/10.1016/j.bandc.2016.07.001

36. Hölzel BK, Carmody J, Evans KC, Hoge EA, Dusek JA, et al. 2010 Stress reduction correlates with structural changes in the amygdala. So Cogn Affect Neurosci 5(1): 11-17. https://doi.org/10.1093/scan/nsp034

37. Tremblay S, Pascual-Leone A, Théoret H. 2018. A review of the effects of physical activity and sports concussion on brain function and anatomy. Int J Psychophysiol 132(Pt A): 167-175. https://doi. org/10.1016/j.ijpsycho.2017.09.005

38. Villemure C, Čeko M, Cotton VA, Bushnell MC. 2015. Neuroprotective effects of yoga practice: age-, experience-, and frequency-dependent plasticity. Front Hum Neurosci 9: 281. https://doi.org/10.3389/ fnhum.2015.00281

39. Villemure C, Ceko M, Cotton VA, Bushnell MC. 2014. Insular cortex mediates increased pain tolerance in yoga practitioners. Cereb Cortex 24(10): 2732-2740. https://doi.org/10.1093/cercor/bht124

40. Gothe NP, Hayes JM, Temali C, Damoiseaux JS. 2018. Differences in brain structure and function among yoga practitioners and controls. Front Integr Neurosci 12: 26. https://doi.org/10.3389/fnint.2018.00026

41. Hariprasad VR, Varambally S, Shivakumar V, Kalmady SV, Venkatasubramanian G, et al. 2013. Yoga increases the volume of the hippocampus in elderly subjects. Indian J Psychiatry 55(Suppl 3): S394-S396. https://doi.org/10.4103/0019-5545.116309

42. Kalyani BG, Venkatasubramanian G, Arasappa R, Rao NP, Kalmady SV, et al. 2011. Neurohemodynamic correlates of 'OM' chanting: a pilot functional magnetic resonance imaging study. Int J Yoga 4(1): 3-6. https://doi.org/10.4103/0973-6131.78171

43. Desai R, Tailor A, Bhatt T. 2015. Effects of yoga on brain waves and structural activation: a review. Complement Ther Clin Pract 21(2): 112118. https://doi.org/10.1016/j.ctcp.2015.02.002

44. Muehsam D, Lutgendorf S, Mills PJ, Rickhi B, Chevalier G, et al. 2017. The embodied mind: a review on functional genomic and neurological correlates of mind-body therapies. Neurosci Biobehav Rev 73: 165-181. https://doi.org/10.1016/j.neubiorev.2016.12.027

45. Gard T, Noggle JJ, Park CL, Vago DR, Wilson A. 2014. Potential selfregulatory mechanisms of yoga for psychological health. Front Hum Neurosci 8: 770. https://doi.org/10.3389/fnhum.2014.00770

46. Kinser PA, Goehler LE, Taylor AG. 2012. How might yoga help depression? A neurobiological perspective. Explore (NY) 8(2): 118-126. https://doi.org/10.1016/j.explore.2011.12.005

47. Tolbaños Roche L, Miró Barrachina MT, Ibáñez Fernández I, Betancort M. 2017. YOGA and self-regulation in management of essential arterial hypertension and associated emotional symptomatology: a randomized controlled trial. Complement Ther Clin Pract 29: 153-161. https://doi. org/10.1016/j.ctcp.2017.09.012

48. Riley KE, Park CL. 2015. How does yoga reduce stress? A systematic review of mechanisms of change and guide to future inquiry. Health Psychol Rev 9(3): 379-396. https://doi.org/10.1080/17437199.2014.981778

49. Kumar A, Rinwa P, Kaur G, Machawal L. 2013. Stress: neurobiology, consequences and management. I Pharm Bioallied Sci 5(2): 91-97. https://doi.org/10.4103/0975-7406.111818

50. Kim EJ, Pellman B, Kim JJ. 2015. Stress effects on the hippocampus: a critical review. Learn Mem 22(9): 411-416. https://doi.org/10.1101/ $\operatorname{lm} .037291 .114$
51. Gianaros PJ, Jennings JR, Sheu LK, Greer PJ, Kuller LH, et al. 2007. Prospective reports of chronic life stress predict decreased grey matter volume in the hippocampus. Neuroimage 35(2): 795-803. https://doi. org/10.1016/j.neuroimage.2006.10.045

52. Erickson KI, Prakash RS, Voss MW, Chaddock L, Heo S, et al. 2010. Brain-derived neurotrophic factor is associated with age-related decline in hippocampal volume. J Neurosci 30(15): 5368-5375. https://doi. org/10.1523/JNEUROSCI.6251-09.2010

53. Mondelli V, Cattaneo A, Murri MB, Di Forti M, Handley R, et al. 2011. Stress and inflammation reduce brain-derived neurotrophic factor expression in first-episode psychosis: a pathway to smaller hippocampal volume. J Clin Psychiatry 72(12): 1677-1684. https://doi.org/10.4088/ JCP.10m06745

54. Lee T, Jarome T, Li SJ, Kim JJ, Helmstetter FJ. 2009. Chronic stress selectively reduces hippocampal volume in rats: a longitudinal magnetic resonance imaging study. Neuroreport 20(17): 1554-1558. https://doi. org/10.1097/WNR.0b013e328332bb09

55. Erickson KI, Voss MW, Prakash RS, Basak C, Szabo A, et al. 2011. Exercise training increases size of hippocampus and improves memory. Proc Natl Acad Sci U S A 108(7): 3017-3022. https://doi.org/10.1073/ pnas.1015950108

56. Barth C, Steele CJ, Mueller K, Rekkas VP, Arélin K, et al. 2016. In-vivo dynamics of the human hippocampus across the menstrual cycle. Sci Rep 6: 32833. https://doi.org/10.1038/srep32833

57. Heany SJ, van Honk J, Stein DJ, Brooks S. 2016. A quantitative and qualitative review of the effects of testosterone on the function and structure of the human social-emotional brain. Metab Brain Dis 31(1): 157-167. https://doi.org/10.1007/s11011-015-9692-y

58. Tramontin AD, Brenowitz EA. 2000. Seasonal plasticity in the adult brain. Trends Neurosci 23(6): 251-258. https://doi.org/10.1016/S01662236(00)01558-7

59. Roguin A. 2006. Scipione Riva-Rocci and the men behind the mercury sphygmomanometer. Int J Clin Pract 60(1): 73-79. https://doi. org/10.1111/j.1742-1241.2005.00548.x

60. Nagarathna R, Nagendra HR. 2007. Yoga. Breathing practices, Asanas, Pranayama, Mudras, Bhandas and Krias, Meditation: Eigenverlag.

61. Ashburner J, Friston KJ. 2000. Voxel-based morphometry--the methods. Neuroimage 11(6 Pt 1): 805-821. https://doi.org/10.1006/ nimg.2000.0582

62. Ashburner J, Friston KJ. 2005. Unified segmentation. Neuroimage 26(3): 839-851. https://doi.org/10.1016/j.neuroimage.2005.02.018

63. Ashburner J. 2007. A fast diffeomorphic image registration algorithm. Neuroimage 38(1): 95-113. https://doi.org/10.1016/j. neuroimage.2007.07.007

64. Spruill TM. 2010. Chronic psychosocial stress and hypertension. Curr Hypertens Rep 12(1): 10-16. https://doi.org/10.1007/s11906-009-0084-8

65. Gasperin D, Netuveli G, Dias-da-Costa JS, Pattussi MP. 2009. Effect of psychological stress on blood pressure increase: a meta-analysis of cohort studies. Cad Saude Publica 25(4): 715-726. https://doi. org/10.1590/S0102-311X2009000400002

66. Ayada C, Toru Ü, Korkut Y. 2015. The relationship of stress and blood pressure effectors. Hippokratia 19(2): 99-108.

67. Wang J, Xiong X, Liu W. 2013. Yoga for essential hypertension: a systematic review. PloS One 8(10): e76357. https://doi.org/10.1371/ journal.pone.0076357

68. Telles S, Yadav A, Kumar N, Sharma S, Visweshwaraiah NK, et al. 2013. Blood pressure and Purdue pegboard scores in individuals with hypertension after alternate nostril breathing, breath awareness, and no intervention. Med Sci Monit 19: 61-66. https://doi.org/10.12659/MSM.883743

69. Cramer H, Haller H, Lauche R, Steckhan N, Michalsen A, et al. 2014. A systematic review and meta-analysis of yoga for hypertension. Am J Hypertens 27(9): 1146-1151. https://doi.org/10.1093/ajh/hpu078 
70. Mizuno J, Monteiro HL. 2013. An assessment of a sequence of yoga exercises to patients with arterial hypertension. J Bodyw Mov Ther 17(1): 35-41. https://doi.org/10.1016/j.jbmt.2012.10.007

71. Cohen DL, Bloedon LT, Rothman RL, Farrar JT, Galantino ML, et al. 2011. Iyengar yoga versus enhanced usual care on blood pressure in patients with prehypertension to stage I hypertension: a randomized controlled trial. Evid Based Complement Alternat Med 2011: 546428 https://doi.org/10.1093/ecam/nep130

72. Hagins M, Rundle A, Consedine NS, Khalsa SB. 2014. A randomized controlled trial comparing the effects of yoga with an active control on ambulatory blood pressure in individuals with prehypertension and stage 1 hypertension. J Clin Hypertens (Greenwich) 16(1): 54-62. https:// doi.org/10.1111/jch.12244

73. Okonta NR. 2012. Does yoga therapy reduce blood pressure in patient with hypertension? an integrative review. Holist Nurs Pract 26(3): $137-$ 141. https://doi.org/10.1097/HNP.0b013e31824ef647

74. Streeter CC, Gerbarg PL, Saper RB, Ciraulo DA, Brown RP. 2012. Effects of yoga on the autonomic nervous system, gammaaminobutyric-acid, and allostasis in epilepsy, depression, and posttraumatic stress disorder. Med Hypotheses 78(5): 571-579. https://doi org/10.1016/j.mehy.2012.01.021

75. Martin JH. 2003. Neuroanatomy. Text and atlas, $3^{\text {rd }}$ (ed), McGraw-Hill, New York, NY, USA.

76. Andersen P, Morris R, Amaral D, Bliss T, O'Keefe J. 2007. The hippocampus book. Oxford University Press, UK.

77. Gluck MA, Mercado E, Myers CE. 2014. Learning and memory: from brain to behavior. Worth Publisher, New York, NY, USA, pp 1-501.

78. Finger S. 2001. Origins of neuroscience: a history of explorations into brain function. Oxford University Press, UK.

79. Maguire EA, Gadian DG, Johnsrude IS, Good CD, Ashburner J, et al. 2000. Navigation-related structural change in the hippocampi of taxi drivers. Proc Natl Acad Sci U S A 97(8): 4398-4403. https://doi. org/10.1073/pnas.070039597

80. Sharp PE. 2002. The neural basis of navigation: evidence from single cell recording. Kluwer Academic, Boston, MA, USA.

81. Zelano C, Jiang H, Zhou G, Arora N, Schuele S, et al. 2016. Nasal respiration entrains human limbic oscillations and modulates cognitive function. J Neurosci 36(49): 12448-12467. https://doi.org/10.1523/ JNEUROSCI.2586-16.2016

82. Nguyen Chi V, Müller C, Wolfenstetter T, Yanovsky Y, Draguhn A 2016. Hippocampal respiration-driven rhythm distinct from theta oscillations in awake mice. J Neurosci 36(1): 162-177. https://doi. org/10.1523/JNEUROSCI.2848-15.2016

83. Harper RM, Poe GR, Rector DM, Kristensen MP. 1998. Relationships between hippocampal activity and breathing patterns. Neurosci Biobehav Rev 22(2): 233-236. https://doi.org/10.1016/S0149-7634(97)00010-9

84. Poe GR, Kristensen MP, Rector DM, Harper RM. 1996. Hippocampal activity during transient respiratory events in the freely behaving cat. Neuroscience 72(1): 39-48. https://doi.org/10.1016/03064522(95)00525-0

85. Lacuey N, Zonjy B, Londono L, Lhatoo SD. 2017. Amygdala and hippocampus are symptomatogenic zones for central apneic seizures. Neurology 88(7): 701-705. https://doi.org/10.1212/ WNL.0000000000003613

86. May A. 2011. Experience-dependent structural plasticity in the adult human brain. Trends Cogn Sci 15(10): 475-482. https://doi. org/10.1016/j.tics.2011.08.002

87. Kuruba R, Hattiangady B, Shetty AK. 2009. Hippocampal neurogenesis and neural stem cells in temporal lobe epilepsy. Epilepsy Behav 14(Suppl 1): 65-73. https://doi.org/10.1016/j.yebeh.2008.08.020

88. Damirchi A, Hosseini F, Babaei P. 2018. Mental training enhances cognitive function and BDNF more than either physical or combined training in elderly women with MCI: a small-scale study. Am J Alzheimers Dis Other Demen 33(1): 20-29. https://doi. org/10.1177/1533317517727068

89. van Praag H, Shubert T, Zhao C, Gage FH. 2005. Exercise enhances learning and hippocampal neurogenesis in aged mice. J Neurosci 25(38): 8680-8685. https://doi.org/10.1523/JNEUROSCI.1731-05.2005

90. Elbrecht C. 2012. Trauma healing at the clay field: a sensorimotor art therapy approach. Jessica Kingsley Publishers, London, UK.

91. Enkavi AZ, Weber B, Zweyer I, Wagner J, Elger CE, et al. 2017. Evidence for hippocampal dependence of value-based decisions. Sci Rep 7(1): 17738. https://doi.org/10.1038/s41598-017-18015-4

92. Cramer H. 2017. Where and how does yoga work? - a scientific overview. Dtsch med Wochenschr 142(25): 1925-1929. https://doi. org/10.1055/s-0043-116158

93. Froeliger BE, Garland EL, Modlin LA, McClernon FJ. 2012. Neurocognitive correlates of the effects of yoga meditation practice on emotion and cognition: a pilot study. Front Integr Neurosci 6: 48. https:// doi.org/10.3389/fnint.2012.00048

94. Maddalena B, Laura P, Paola G. 2015. The meditative mind: a comprehensive meta-analysis of MRI studies. Biomed Res Int 2015: 419808. https://doi.org/10.1155/2015/419808

95. Leung MK, Chan CC, Yin J, Lee CF, So KF, et al. 2013. Increased gray matter volume in the right angular and posterior parahippocampal gyri in loving-kindness meditators. Soc Cogn Affect Neurosci 8(1): 34-39. https://doi.org/10.1093/scan/nss076

96. Luders E, Toga AW, Lepore N, Gaser C. 2009. The underlying anatomical correlates of long-term meditation: larger hippocampal and frontal volumes of gray matter. Neuroimage 45(3): 672-678. https://doi. org/10.1016/j.neuroimage.2008.12.061

97. Squire LR, Genzel L, Wixted JT, Morris RG. 2015. Memory consolidation. Cold Spring Harb Perspect Biol 7(8): a021766. https://doi. org/10.1101/cshperspect.a021766

98. Anderson EB, Grossrubatscher I, Loren F. 2014. Dynamic hippocampal circuits support learning- and memory-guided behaviors. Cold Spring Harbor Symposia on Quantitative Biology 79: 51-58. https://doi. org/10.1101/sqb.2014.79.024760

99. Gothe NP, Kramer AF, McAuley E. 2014. The effects of an 8-week Hatha yoga intervention on executive function in older adults. $J$ Gerontol A Biol Sci Med Sci 69(9): 1109-1116. https://doi.org/10.1093/ gerona/glu095

100.Gothe N, Pontifex MB, Hillman C, McAuley E. 2013. The acute effects of yoga on executive function.J Phys Act Health 10(4): 488-495. https:// doi.org/10.1123/jpah.10.4.488

101.Burgess N, Maguire EA, O'Keefe J. 2002. The human hippocampus and spatial and episodic memory. Neuron 35(4): 625-641. https://doi. org/10.1016/S0896-6273(02)00830-9

102.Albouy G, Sterpenich V, Balteau E, Vandewalle G, Desseilles M, et al. 2008. Both the hippocampus and striatum are involved in consolidation of motor sequence memory. Neuron 58(2): 261-272. https://doi. org/10.1016/j.neuron.2008.02.008

103.Hüfner K, Binetti C, Hamilton DA, Stephan T, Flanagin VL, et al. 2011. Structural and functional plasticity of the hippocampal formation in professional dancers and slackliners. Hippocampus 21(8): 855-865. https://doi.org/10.1002/hipo.20801

104.Niemann C, Godde B, Voelcker-Rehage C. 2014. Not only cardiovascular, but also coordinative exercise increases hippocampal volume in older adults. Front Aging Neurosci 6: 170. https://doi. org/10.3389/fnagi.2014.00170

105.Rehfeld K, Müller P, Aye N, Schmicker M, Dordevic M, et al. 2017. Dancing or fitness sport? The effects of two training programs on hippocampal plasticity and balance abilities in healthy seniors. Front Hum Neurosci 11: 305. https://doi.org/10.3389/fnhum.2017.00305

106.Sehm B, Taubert M, Conde V, Weise D, Classen J, et al. 2014. Structural brain plasticity in Parkinson's disease induced by balance 
training. Neurobiol Aging 35(1): 232-239. https://doi.org/10.1016/j. neurobiolaging.2013.06.021

107.Liu Y, McAfee SS, Heck DH. 2017. Hippocampal sharp-wave ripples in awake mice are entrained by respiration. Sci Rep 7: 8950. https://doi. org/10.1038/s41598-017-09511-8

108.Bouslama M, Adla-Biassette H, Ramanantsoa N, Bourgeois T, Bollen B, et al. 2015. Protective effects of intermittent hypoxia on brain and memory in a mouse model of apnea of prematurity. Front Physiol 6: 313 . https://doi.org/10.3389/fphys.2015.00313

109. Critchley HD, Nicotra A, Chiesa PA, Nagai Y, Gray MA, et al. 2015. Slow breathing and hypoxic challenge: cardiorespiratory consequences and their central neural substrates. PloS One 10(5): e0127082. https:// doi.org/10.1371/journal.pone.0127082

110.Manukhina EB, Downey HF, Shi X, Mallet RT. 2016. Intermittent hypoxia training protects cerebrovascular function in Alzheimer's disease. Exp Biol Med (Maywood) 241(12): 1351-1363. https://doi. org/10.1177/1535370216649060

111.Malshe PC. 2011. Nisshesha rechaka pranayama offers benefits through brief intermittent hypoxia. Ayu 32(4): 451-457. https://doi. org/10.4103/0974-8520.96114

112.Ajayi IE, Mills PC. 2017. Effects of the hippocampus on the motor expression of augmented breaths. PLoS One 12(8): e0183619. https:// doi.org/10.1371/journal.pone.0183619

113. Ramirez JM. 2014. The integrative role of the sigh in psychology, physiology, pathology, and neurobiology. Prog Brain Res 209: 91-129. https://doi.org/10.1016/B978-0-444-63274-6.00006-0

114.Smith MA. 1996. Hippocampal vulnerability to stress and aging: possible role of neurotrophic factors. Behav Brain Res 78(1): 25-36. https://doi.org/10.1016/0166-4328(95)00220-0

115.Yamada K, Nabeshima T. 2003. Brain-derived neurotrophic factor/ TrkB signaling in memory processes. J Pharmacol Sci 91(4): 267-270. https://doi.org/10.1254/jphs.91.267

116. Raju T, Nagendra HR. 2017. Yoga induced brain plasticity- role of neurotrophic factors. In: Open Access J Neurol Neurosurg 6(1): 555680 https://doi.org/10.19080/OAJNN.2017.06.555680

117.Cahn BR, Goodman MS, Peterson CT, Maturi R, Mills PJ. 2017. Yoga, meditation and mind-body health: Increased BDNF, cortisol awakening response, and altered inflammatory marker expression after a 3-month yoga and meditation retreat. Front Hum Neurosci 11: 315 https://doi.org/10.3389/fnhum.2017.00315

118.Mackay CP, Kuys SS, Brauer SG. 2017. The effect of aerobic exercise on brain-derived neurotrophic factor in people with neurological disorders: a systematic review and meta-analysis. Neural Plast 2017: 4716197. https://doi.org/10.1155/2017/4716197

119.Jeon YK, $\mathrm{Ha} \mathrm{CH}$. 2017. The effect of exercise intensity on brain derived neurotrophic factor and memory in adolescents. Environ Health Prev Med 22(1): 27. https://doi.org/10.1186/s12199-017-0643-6

120.Chapleau M, Aldebert J, Montembeault M, Brambati SM. 2016. Atrophy in Alzheimer's disease and semantic dementia. An ALE metaanalysis of voxel-based morphometry studies. J Alzheimers Dis 54(3): 941-955. https://doi.org/10.3233/JAD-160382

121.Wise T, Radua J, Via E, Cardoner N, Abe O, et al. 2017. Common and distinct patterns of grey-matter volume alteration in major depression and bipolar disorder: evidence from voxel-based meta-analysis. Mol Psychiatry 22(10): 1455-1463. https://doi.org/10.1038/mp.2016.72

122.Zhou H, Li R, Ma Z, Rossi S, Zhu X, et al. 2016. Smaller gray matter volume of hippocampus/parahippocampus in elderly people with subthreshold depression: a cross-sectional study. BMC Psychiatry 16 219. https://doi.org/10.1186/s12888-016-0928-0
123.Moon CM, Jeong GW. 2017. Abnormalities in gray and white matter volumes associated with explicit memory dysfunction in patients with generalized anxiety disorder. Acta Radiol 58(3): 353-361. https://doi. org $/ 10.1177 / 0284185116649796$

124.Meng Y, Qiu C, Zhu H, Lama S, Lui S. 2014. Anatomical deficits in adult posttraumatic stress disorder: a meta-analysis of voxel-based morphometry studies. Behav Brain Res 270: 307-315. https://doi. org/10.1016/j.bbr.2014.05.021

125.Singh S, Khushu S, Kumar P, Goyal S, Bhatia T. 2018. Evidence for regional hippocampal damage in patients with schizophrenia. Neuroradiology 60(2): 199-205. https://doi.org/10.1007/s00234-0171954-4

126.Mooventhan A, Nivethitha L. 2017. Evidence based effects of yoga in neurological disorders. J Clin Neurosci 43: 61-67. https://doi. org/10.1016/j.jocn.2017.05.012

127.DiStasio SA. 2008. Integrating yoga into cancer care. Clin J Oncol Nurs 12(1): 125-130. https://doi.org/10.1188/08.CJON.125-130

128. Krishnakumar D, Hamblin MR, Lakshmanan S. 2015. Meditation and yoga can modulate brain mechanisms that affect behavior and anxiety-a modern scientific perspective. Anc Sci 2(1): 13-19. https://doi. org/10.14259/as.v2i1.171

129.Streeter CC, Whitfield TH, Owen L, Rein T, Karri SK, et al. 2010. Effects of yoga versus walking on mood, anxiety, and brain GABA levels. A randomized controlled MRS study. J Altern Complement Med 16(11): 1145-1152. https://doi.org/10.1089/acm.2010.0007

130.Campbell, Stephanie; Macqueen, Glenda. 2004. The role of the hippocampus in the pathophysiology of major depression. J Psychiatry Neurosci 29(6): 417-426.

131.Butler O, Willmund G, Gleich T, Gallinat J, Kühn S, et al. 2018. Hippocampal gray matter increases following multimodal psychological treatment for combat-related post-traumatic stress disorder. Brain Behav 8(5): e00956. https://doi.org/10.1002/brb3.956

132.Gbyl K, Videbech P. 2018. Electroconvulsive therapy increases brain volume in major depression. a systematic review and meta-analysis. Acta Psychiatr Scand 138(3): 180-195. https://doi.org/10.1111/acps.12884

133.Taki Y, Hashizume H, Sassa Y, Takeuchi H, Asano M, et al. 2012. Correlation among body height, intelligence, and brain gray matter volume in healthy children. Neuroimage 59(2): 1023-1027. https://doi. org/10.1016/j.neuroimage.2011.08.092

134. Ritchie SJ, Cox SR, Shen X, Lombardo MV, Reus LM, et al. 2018. Sex differences in the adult human brain: evidence from 5216 UK biobank participants Cereb Cortex 28(8): 2959-2975. https://doi.org/10.1093/ cercor/bhy109

135.Kanai R, Rees G. 2011. The structural basis of inter-individual differences in human behaviour and cognition. Nat Rev Neurosci 12(4): 231-242. https://doi.org/10.1038/nrn3000

136.Gianaros PJ, Sheu LK, Uyar F, Koushik J, Jennings JR, et al. 2017. A brain phenotype for stressor-evoked blood pressure reactivity. $\mathrm{J} \mathrm{Am}$ Heart Assoc 6(9): e006053. https://doi.org/10.1161/JAHA.117.006053

137.Kim JJ, Diamond DM. 2002. The stressed hippocampus, synaptic plasticity and lost memories. Nat Rev Neurosci 3(6): 453-462. https:// doi.org/10.1038/nrn849

138. Grigoryan G, Segal M. 2016. Lasting differential effects on plasticity induced by prenatal stress in dorsal and ventral hippocampus. Neural Plast 2016: 2540462. https://doi.org/10.1155/2016/2540462

139. Gilbertson MW, Shenton ME, Ciszewski A, Kasai K, Lasko NB, et al. 2002. Smaller hippocampal volume predicts pathologic vulnerability to psychological trauma. Nat Neurosci 5(11): 1242-1247. https://doi. org $/ 10.1038 / \mathrm{nn} 958$ 